\begin{tabular}{|c|c|c|}
\hline $\begin{array}{l}\text { PKS } \\
\text { PUBLIC } \\
\text { KNOLLEDEGE } \\
\text { PROECC }\end{array}$ & $\begin{array}{c}\text { Revista de GEOGRAFIA } \\
\text { (RECIFE) } \\
\text { http://www.revistaufpe.br/revistageografia }\end{array}$ & 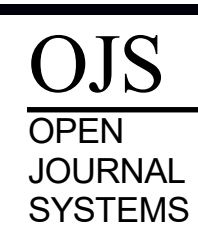 \\
\hline
\end{tabular}

\title{
OS ESPAÇOS NAS ESTRATÉGIAS DOS GRUPOS UMBANDISTAS PARA O EXERCÍCIO DE CIDADANIA NA CIDADE DO RIO DE JANEIRO
}

\author{
Marcelo Alonso Morais ${ }^{1}$ \\ ${ }^{1}$ Doutor em Geografia pela Universidade Federal do Rio de Janeiro. Professor da Pontifica Universidade \\ Católica do Rio de Janeiro. Email: alonsomarcelogeo@yahoo.com.br
}

Artigo recebido em 22/08/2017 e aceito em 01/10/2017

\begin{abstract}
RESUMO
No Município do Rio de Janeiro, a crescente intolerância religiosa, a dificuldade de acesso aos espaços públicos e de manutenção dos espaços privados, além da necessidade de adaptação das religiões à Constituição Brasileira, vem levando grupos umbandistas a criarem estratégias espaciais que possibilitem reconhecimento, visibilidade e efetividade de decisões que atendam às demandas de cidadania. Este artigo tem como objetivo refletir sobre como os espaços fazem parte das estratégias dos grupos umbandistas no exercício da cidadania na cidade do Rio de Janeiro, tornando-se um referencial que interfere no processo de construção identitário e cria o sentimento de pertencimento, as redes de solidariedade e o reconhecimento no/do espaço.
\end{abstract}

Palavras-chaves: Espaço. Religião. Cidadania.

\section{THE SPACES IN THE STRATEGIES OF THE UMBANDIST GROUPS FOR THE EXERCISE OF CITIZENSHIP IN THE CITY OF RIO DE JANEIRO}

\begin{abstract}
In the Municipality of Rio de Janeiro, growing religious intolerance, the difficulty of access to public spaces and the maintenance of private spaces, and the need to adapt religions to the Brazilian Constitution, have led Umbandist groups to create spatial strategies that allow for recognition, visibility and effectiveness of decisions that meet the demands of citizenship. This article aims to reflect on how the spaces are part of the strategies of Umbandist groups in the exercise of citizenship in the city of Rio de Janeiro, becoming a referential that interferes in the process of identity construction and creates the feeling of belonging, the networks of solidarity and recognition in the space.
\end{abstract}

Keywords: Space. Religion. Citizenship. 


\section{INTRODUÇÃO}

Para que os mais diversos grupos possam construir o direito de fazer parte / estar no espaço, concebido aqui como o espaço do compartilhamento entre diferentes, onde emergem conflitos de interesses e comportamentos, há a necessidade de acordos e regulações. Dessa maneira, acreditamos que o entendimento das práticas espaciais religiosas pode ser um instrumento na construção de políticas públicas que levem em conta as necessidades materiais e imateriais das populações envolvidas, criando, assim, condição de cidadania num contexto democrático.

Fruto de um expressivo sincretismo religioso, a Umbanda se constitui em uma religião brasileira que sacraliza os orixás africanos e os espíritos ancestrais dos grupos indígenas, aproximando-os de santos cristãos, além de apresentar enorme influência das práticas kardecistas, como a lei do carma e a caridade (BROWN, 1986; MORAIS, 2009, 2010, 2012, 2013, 2014). Essa religiosidade, apesar do declínio percentual e absoluto de seus praticantes até 2000, revela uma ligeira recuperação em 2010 (ALMEIDA e BARBOSA, 2015), sendo que boa parte de seus praticantes se concentram em metrópoles como a cidade do Rio de Janeiro. No entanto, apesar de minorias em termos quantitativos, os umbandistas são vítimas constantes na esfera do conflito nos casos de intolerância contra as práticas religiosas que possuem matrizes africanas. Segundo o Mapeamento das Casas de Religiões de Matriz Africana do Estado do Rio, feito pelo Núcleo Interdisciplinar de Reflexão e Memória Afrodescendente (Nirema) da PUC-Rio, mais da metade das casas de Umbanda ou Candomblé do estado do Rio de Janeiro sofreram algum tipo de discriminação. Segundo a pesquisa, das 847 casas pesquisadas desde 2008, mais da metade (430 delas) relatou episódios de intolerância religiosa contra seus centros ou seguidores nos últimos anos. ${ }^{1}$

Além dos ataques sofridos pelos praticantes, os umbandistas também enfrentam um outro desafio: a necessidade do uso dos espacos na metrópole, em especial os espacos públicos para a realizacão dos rituais. Os umbandistas, cidadãos e moradores da cidade do Rio de Janeiro, se apropriam dos espaços, transformam-os em espaço sagrado, ou seja, em locus da hierofania revelada em objetos (ROSENDAHL, 2002, 2012), através de rituais e/ou da manifestação direta da divindade. Para muitos crentes, desprovidos de reverenciar, in loco, as forças energéticas que emanam das encruzilhadas, cemitérios, praças, rochas, águas, solos, árvores e folhas (MORAIS, 2010, 2012, 2013; BROWN, 1986), torna-se fundamental o uso

${ }^{1}<$ http://oglobo.globo.com/rio/religioes-africanas-merce-da-intolerancia-8471972>. Acesso em: 28 de agosto de 2013. 
de espaços públicos. Diante dessa problemática, o presente artigo possui alguns objetivos. Primeiramente, discutir sobre a relevância do espaço para os rituais umbandistas e, consequentemente, o exercício de sua cidadania, quando, em diferentes práticas e momentos, se apropriam desse espaco e o transformam em espaço sagrado. A seguir, o texto apresentará alguns conflitos que ocorrem com frequência entre os umbandistas e outros grupos da sociedade na disputa por espaços. Finalmente, a partir de um estudo de casos, revelaremos algumas estratégias que estão sendo construídas para o uso dos espaços.

\section{A IMPORTÂNCIA DO ESPAÇO COMO INSTRUMENTO DE EXERCÍCIO DE CIDADANIA PARA OS GRUPOS UMBANDISTAS NA METRÓPOLE CARIOCA}

A demanda por espaço se faz cada vez mais urgente diante da realidade socioespacial vivida pelos umbandistas na cidade do Rio de Janeiro. No espaço metropolitano carioca, a religiosidade umbandista sofre com o preconceito e pressões cada vez mais crescentes de vários grupos dos movimentos pentecostais ${ }^{2}$ e neopentecostais ${ }^{3}$, que invadem e depredam templos, e criam imagens da religião relacionadas a práticas e rituais demoníacos que constroem no imaginário social a ideia de que os seus cultos referendam um paganismo prémoderno entrelaçado à bruxaria e aos espíritos atrasados. Os artefatos e os rituais são satanizados por fiéis de certas igrejas evangélicas que defendem a "Verdade", sendo as tradições umbandistas colocadas na clandestinidade como imagens de um Brasil atrasado, a partir da lógica desenvolvimentista da modernidade. Isso é fruto daquilo que Leite (2014), ao analisar como a liberdade religiosa foi entendida ao longo das constituições republicanas, considera como uma concepção de liberdade religiosa atrelada aos valores cristãos. Essa

\footnotetext{
${ }^{2}$ Ramo das igrejas cristãs ocidentais, o movimento pentecostal nasceu nos Estados Unidos, em 1901, e crê que o Espírito Santo continua a se manifestar nos dias de hoje, da mesma forma que em Pentecostes, na narrativa do Novo Testamento (Atos 2). O pentecostalismo acredita nos dons da glossolalia (o de falar línguas desconhecidas), da cura e da profecia e chegou ao país em 1910, com a fundação da Congregação Cristã do Brasil, na Cidade de São Paulo. Atualmente, existem centenas de igrejas, e as principais, além da Congregação Cristã no Brasil, são: Assembléia de Deus (Pará, 1911), Evangelho Quadrangular (São Paulo, 1953), O Brasil para Cristo (São Paulo, 1955) e Deus é Amor (São Paulo, 1962). (Adaptado de www.pime.org.br. Acessado em 09 de abril de 2009).

${ }^{3}$ Neopentecostalismo é o nome que se dá aos pentecostais da terceira geração (surgidos ao final dos anos de 1970). São assim chamados porque diferem muito dos pentecostais históricos e dos da segunda geração. Não se apegam à questão de roupas, de televisão, de costumes, e têm um jeito diferente de falar sobre Deus. Dualizam o mudo espiritual dividindo-o entre Deus e o Diabo e, para eles, o mundo está completamente tomado por demônios, sendo que a sua função é expulsá-los. Pregam a prosperidade como meio de vida, já que a pobreza é coisa de Satanás, assim como a doença, cuja origem é o demônio, só atingindo quem não acredita em Deus. No Brasil, a maior igreja neopentecostal é a Universal do Reino de Deus (IURD).(Adaptado de Gilberto Stefano. http://www.solascriptura-tt.org. Acessado em 08 de abril de 2009).
} 
aproximação entre o Estado e a religião católica gerou no Brasil uma ideia de liberdade religiosa insatisfatória, deixando à margem religiões que eram consideradas perturbadoras da ordem pública e dos "bons costumes". Para o autor, essa tensão entre Estado laico e o Cristianismo, especialmente o representado pela Igreja Católica Apostólica Romana, se deu pelo número expressivo de praticantes do catolicismo presentes no quadro administrativo do Estado.

Muitos grupos umbandistas presentes na cidade do Rio de Janeiro utilizam espaços chamados de terreiros/templos, que, feito territórios pelos praticantes umbandistas, são bens privados, de acesso público utilizados pelos crentes e visitantes, com estatutos legais e uma hierarquia que se apóia na "circulacão de bens simbólicos sociais que se refletem nas reuniões e sessões mediante os papéis representados pelos médiuns e pela diretoria administrativa" (VICTORIANO, 2005, p.162). O autor supracitado deixa claro que nos terreiros novas territorialidades se constituem, expressas nos papéis rituais, no uso de determinados objetos, no controle e comunicação com as entidades, assim como na incorporação e administração do terreiro de Umbanda. Portanto, é no terreiro que os médiuns, hierarquicamente divididos, manifestam práticas de socialização e familiarização do sagrado (MORAES, 2009, p.43), ressignificando o drama individual dos consulentes que podem "compensar o seu desprestígio em espaços sociais externos" (VICTORIANO, 2005, p.35).

Nesse sentido, as imagens dos santos católicos sincretizados com os orixás, organizados hierarquicamente no gongá (altar) de acordo com os "santos" que regem a casa, a disposição dos bancos, médiuns, oferendas e flores, possuem forte valor simbólico, elemento constituinte da identidade que se territorializa, no fazer do território-santuário na Umbanda (Figura 1). 
Figura 1 - Templo Espírita Vó Sá Maria da Bahia - Festa em homenagem aos orixás Iansã e Oxum

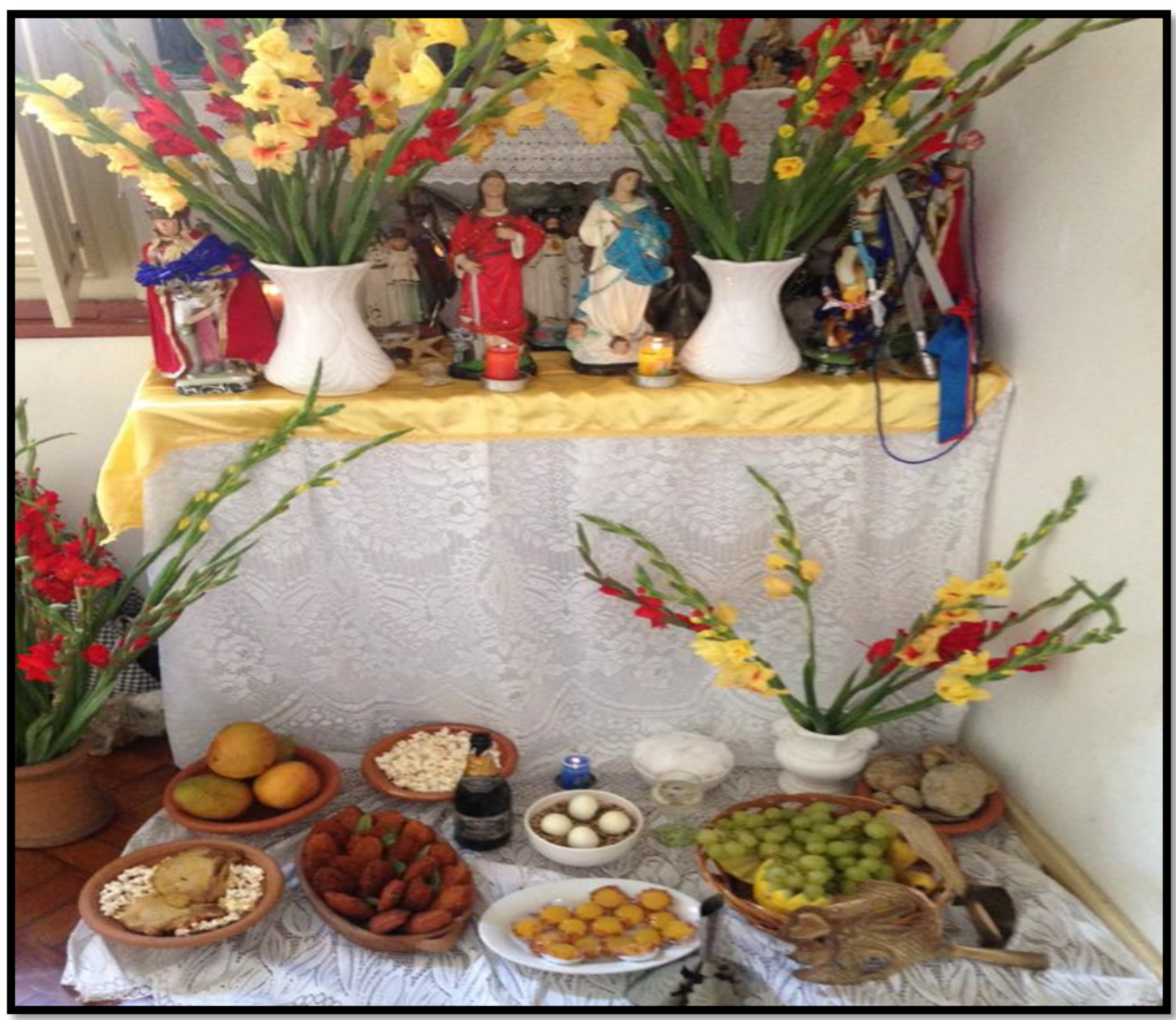

Fonte: Arquivo pessoal (2016)

Cabe ressaltar que, no que diz respeito ao espaço privado, há muitos desafios à realização das práticas rituais, como o custo de alocação de um imóvel para a realização das sessões, a não legalização de muitos terreiros que garantiriam recursos do poder público para ações sociais, a pressão de vizinhos que reclamam do barulho e/ou apresentam atitudes intolerantes diante da ritualística, limitações físicas das propriedades e adequação às leis municipais, como as do silêncio e do lixo.

Além dos espaços internos do terreiro, espaços externos como um rio, uma rocha, o mar e as matas também são sacralizados pelos umbandistas. Muitos de seus símbolos identitários estão calcados em referenciais materiais, apesar de fazerem parte do imaginário. Para os umbandistas, muitos acidentes geográficos, assim como ruas e encruzilhadas, são sacralizados pelos praticantes como símbolos de divindades como os orixás Oxóssi, Oxum, 
Iemanjá, Oxalá e Xangô. Esses ambientes, que também se constituem em territóriossantuários, "espaços de comunhão com um conjunto de signos e valores" (BONNEMAISON, 2002, p.109), são chamados de geossímbolos, ou seja,

um lugar, um itinerário, acidentes geográficos ou uma extensão, que, por motivos políticos, religiosos ou culturais, sob as expectativas individuais ou coletivas de determinados grupos étnicos, assume uma dimensão simbólica, estabelecendo e consolidando, através da prática cultural, seus processos de identidade e alteridade frente aos outros grupos, configurando, assim, a semiografia do território (p.166167).

Como muitos terreiros não possuem esses elementos naturais dentro da propriedade privada, torna-se uma demanda fundamental o acesso a espaços públicos. No entanto, a utilização de determinados locais pelos grupos umbandistas, apesar de não serem locais propriamente de culto, como parques, praças e jardins, gera conflitos, por exemplo, entre a liberdade religiosa, garantida por lei, e a necessidade de proteção desses espaços, que também possuem amparo da legislação vigente, como podemos perceber no artigo 225 da Constituição Federal de 1988 que, ao deixar claro que todos tem direito ao meio ambiente ecologicamente equilibrado, exige do poder público meios de protegê-los. Isso vem provocando o "espraiamento de práticas religiosas que anteriormente eram mais restritas às metrópoles" (ALMEIDA e BARBOSA, 2015, p.347) e leva o umbandista a ter que negociar o uso dos espaços propícios aos cultos.

Portanto, um dos grandes desafios que se coloca diante de vários grupos umbandistas na cidade do Rio de Janeiro seria o de como exercer a sua cidadania diante dos conflitos que emergem entre os crentes e os demais cidadãos pelo uso dos espaços, principalmente aqueles que possuem a presença de leitos d'água, florestas e campos, essenciais para a realização de muitas oferendas. Soma-se a esse fato o crescimento urbano, que vem limitando cada vez mais o acesso aos rios, às cachoeiras e florestas. Como exemplo, podemos citar a Zona Norte da cidade do Rio de Janeiro, que apresenta um expressivo número de terreiros e/ou casas de Umbanda. Ao contrário da Zona Sul da cidade, região onde encontramos inúmeras praias (Copacabana, Ipanema, Urca), vegetação de floresta e cachoeiras (Parque Nacional da Tijuca) e formações rochosas (Pedra da Gávea, Corcovado) que são verdadeiros santuários para a entrega de oferendas à Iemanjá, Oxóssi, Oxum e Xangô, respectivamente. 
Um exemplo de como os espaços territorializados pelos umbandistas como santuários provocam, muitas vezes, reações contrárias de outros cidadãos, dada a ocorrência de cerimônias em vias públicas, pode ser percebido nos rituais para as entidades conhecidas como exus, manifestações de espíritos desencarnados que possuem uma missão evolutiva no plano material.

Em alguns terreiros de Umbanda, os médiuns fazem suas oferendas a essas entidades em potes de barro chamados de alguidares, quepodem conter, de acordo com o exu cultuado, farofa de dendê, carne vermelha crua, frutas, salames, camarões e peixes, acompanhados de cachaça (marafo), cerveja (marambaia) e charutos. Quando os alguidares estão prontos, devem ser dispostos numa "mesa" (geralmente uma toalha branca estendida no chão), com as garrafas de bebida, velas e flores ao redor. Após o ritual no espaco privado do terreiro (que ocorre com a manifestacão dos espíritos nos corpos dos mediuns da casa), geralmente a partir da meia noite, as oferendas devem ser colocadas, de preferência, em ruas, encruzilhadas e/ou portas de cemitério. No entanto, esses espacos públicos não são exclusivos dos umbandistas, pois além de várias ruas da cidade serem espacos de circulacão de veículos e outros grupos da sociedade, outras ruas, residenciais, com respaldo legal, prezam pelo silêncio de seus moradores. Uma festa para os exus, portanto, acaba gerando reações adversas com agressões verbais e físicas, sendo comum, por exemplo, o lançamento de água e objetos das janelas dos prédios, impedindo o desenrolar da cerimônia.

Ao lado dos problemas retratados acima, os umbandistas se deparam com outro obstáculo ao reconhecimento e respeito às suas práticas: a poluição dos pontos de força, (santuários naturais, sítios sagrados ou mesmo casa dos orixás), pelos próprios praticantes da religião. Tecidos, copos e sacos plásticos, estilhaços de garrafas, alguidares, frutas e outros utensílios são deixados em ruas, parques e jardins, poluindo o ambiente. Muitos alegam que esses objetos, imantados durante a cerimônia, não devem ser levados com o médium ou consulente, já que energias negativas que foram "despachadas" podem se apropriar do indivíduo, prejudicando-o. Essa situação se agrava com o uso de velas, que podem causar incêndios florestais, e frutas, pois, se estas são aparentemente inofensivas por serem biodegradáveis, inserem-se artificialmente no ecossistema, além de conterem, muitas vezes, agrotóxicos. Dessa forma, ocorre uma contradição: se a Umbanda só existe por receber vibrações energéticas provenientes da natureza, a poluição dos santuários se torna prejudicial à manutenção da religião e prejudica a imagem do umbandista diante da opinião pública, já que passam a ser vistos, por muitos, como produtores de lixo urbano. 
Portanto, a emergência de reivindicações, não necessariamente de grupos organizados, em busca de reconhecimento e visibilidade das diferenças, torna relevante compreender "como os atores, individualmente ou em grupo, mobilizam dispositivos discursivos, jurídicos e simbólicos para fazer valer suas demandas diante de seus interlocutores" (MOTA, 2014, p.28). Sendo assim, iremos apresentar, a seguir, duas estratégias que dois grupos umbandistas cariocas estão construindo com o intuito de realizar seus rituais, exercendo a liberdade de culto sem desrespeitar a legislação.

Os membros do Grupo Espírita Vó Sá Maria da Bahia, localizado no bairro de Botafogo, Zona Sul da cidade do Rio de Janeiro, utilizam o Parque Ecológico dos Orixás, no município de Magé, Região Metropolitana do Rio de Janeiro, administrado pelo dono da propriedade e presidente da União Umbandista dos Cultos Afro-Brasileiros (UUCAB), sediada na Rua Edgar Romero, n. 81, Sala 334, Madureira. Essa entidade, com personalidade jurídica e reconhecida em âmbito nacional, tem como função primordial legalizar templos de Umbanda, Candomblé e demais cultos afro-brasileiros, mas também oferece atendimento oftalmológico, dentário (em várias clínicas credenciadas nas zonas Norte e Oeste da cidade, assim como dá assistência jurídica e realiza batizados e casamentos.

Para os terreiros, a UUCAB fornece alvará de funcionamento, estatutos, diplomas e toda documentação necessária para que os templos ou terreiros possam funcionar legalmente. Para ser sócio e desfrutar do local, os templos devem se cadastrar e pagar uma anuidade, além de uma taxa pela manutenção do parque, cuja gestão é realizada pelo dirigente da federação citada anteriormente. Este espaço privado oferece locais apropriados para os rituais umbandistas (espaços no centro da mata, com cachoeira próxima), além de banheiros, piscina, lanchonete, áreas para churrasco e estacionamentos (Figuras 2 e 3). 
Figuras 2 e 3 - Entrada do Parque Ecológico dos Orixás e o estacionamento, em Magé $(\mathrm{RJ})$
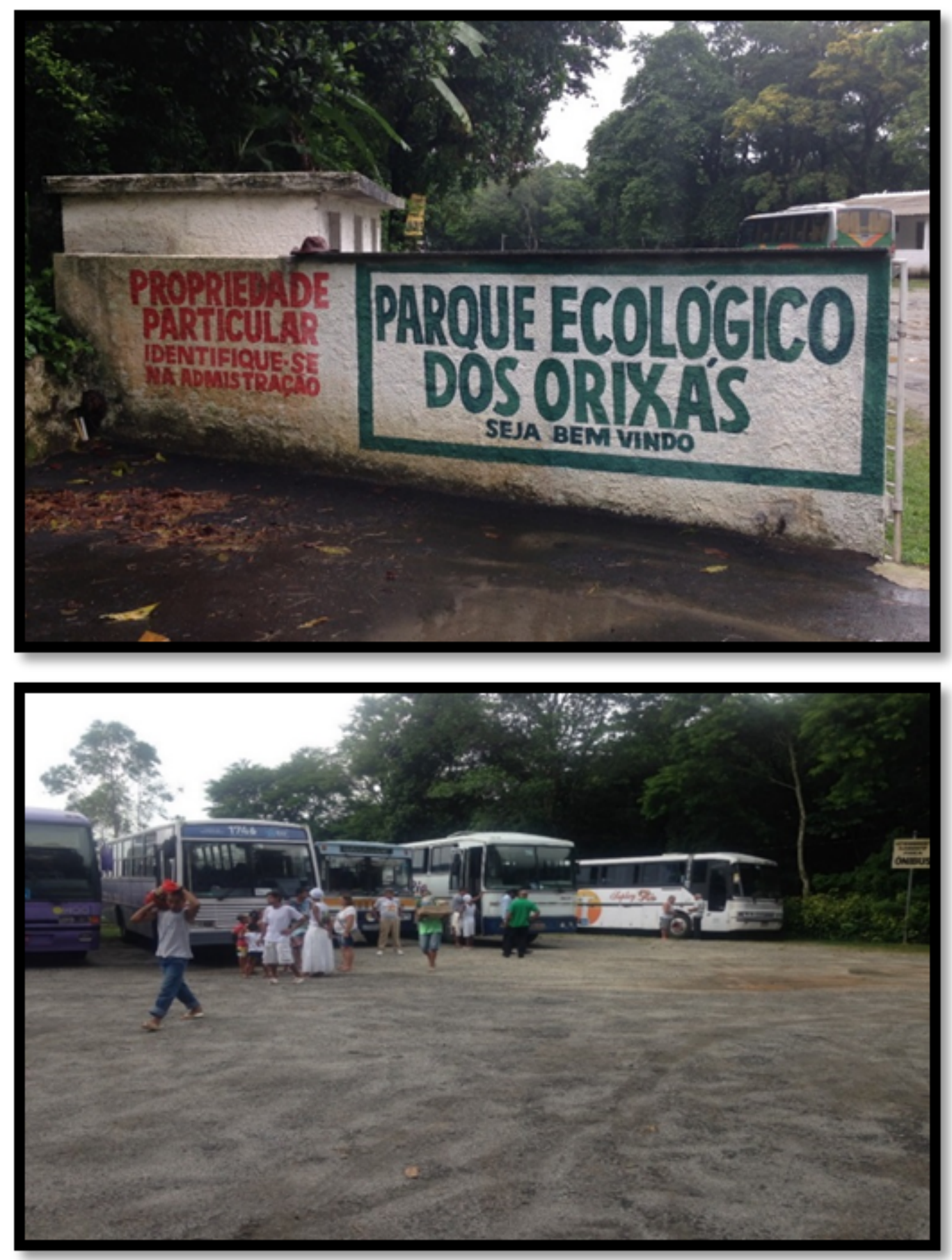

Fonte: Arquivo pessoal $(2016,2017)$.

A dirigente do terreiro, no ato da reserva, tem que estar com a anuidade em dia. Além disso, paga a taxa de manutenção e assina um documento onde se compromete a não deixar resíduos e acender velas próximas às árvores. Este documento revela o compromisso 
assumido pelo terreiro no uso do espaço privado. Infelizmente, nem sempre essa atitude vai se manifestar nos espaços públicos, como veremos a seguir.

Iniciando os rituais, os umbandistas encontram, logo na entrada do parque, pequenas casas separadas por módulos que contém imagens de orixás e entidades de Umbanda, como os exus e os pretos (as) velhos (as). Neste local, os devotos agraciam as entidades/divindades, geralmente, com velas e/ou bebidas (Figuras 4 e 5 ).

Figuras 4 e 5 - Casas com entidades e orixás de Umbanda, Parque Ecológico dos Orixás, em Magé (RJ)

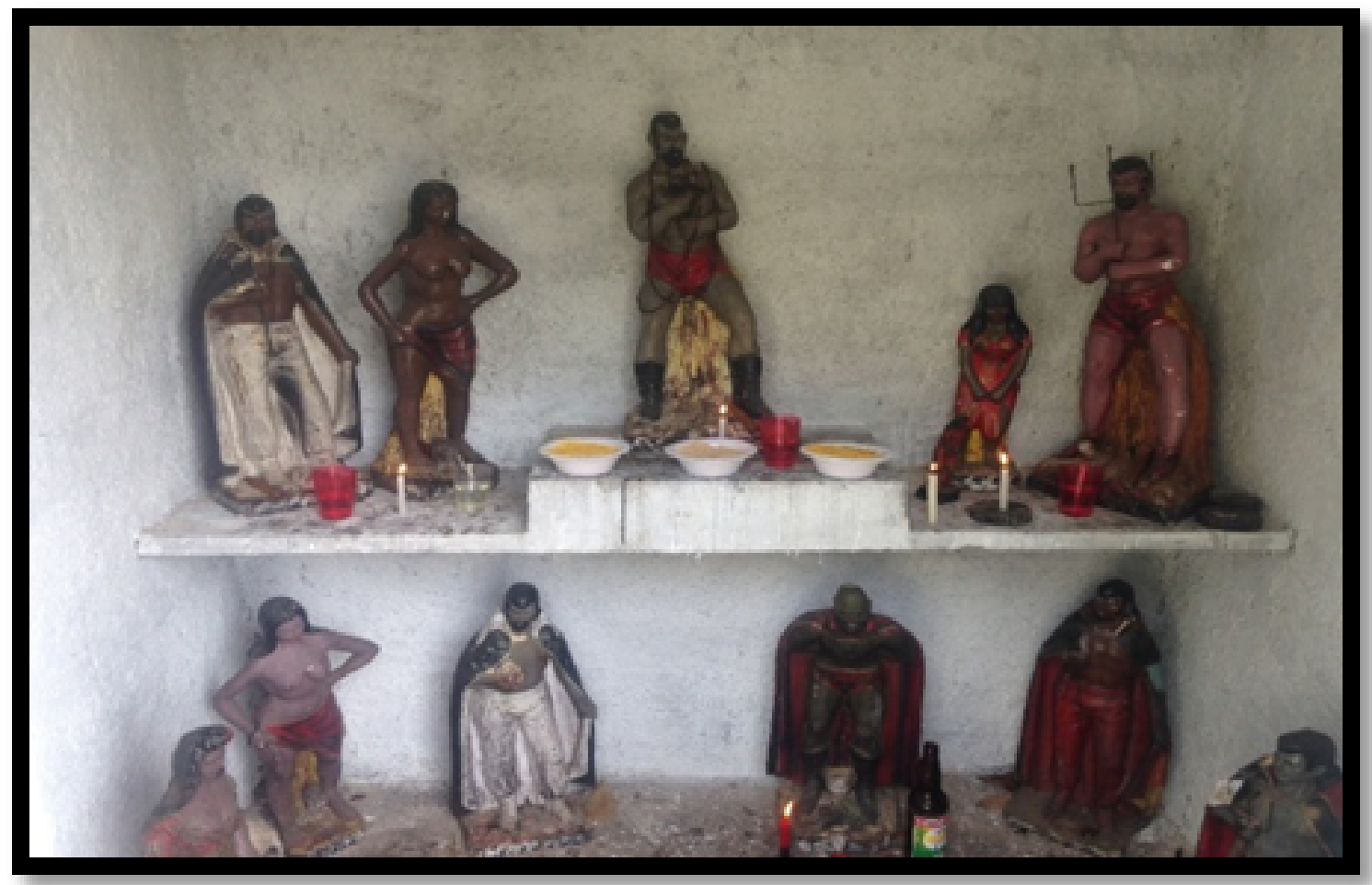




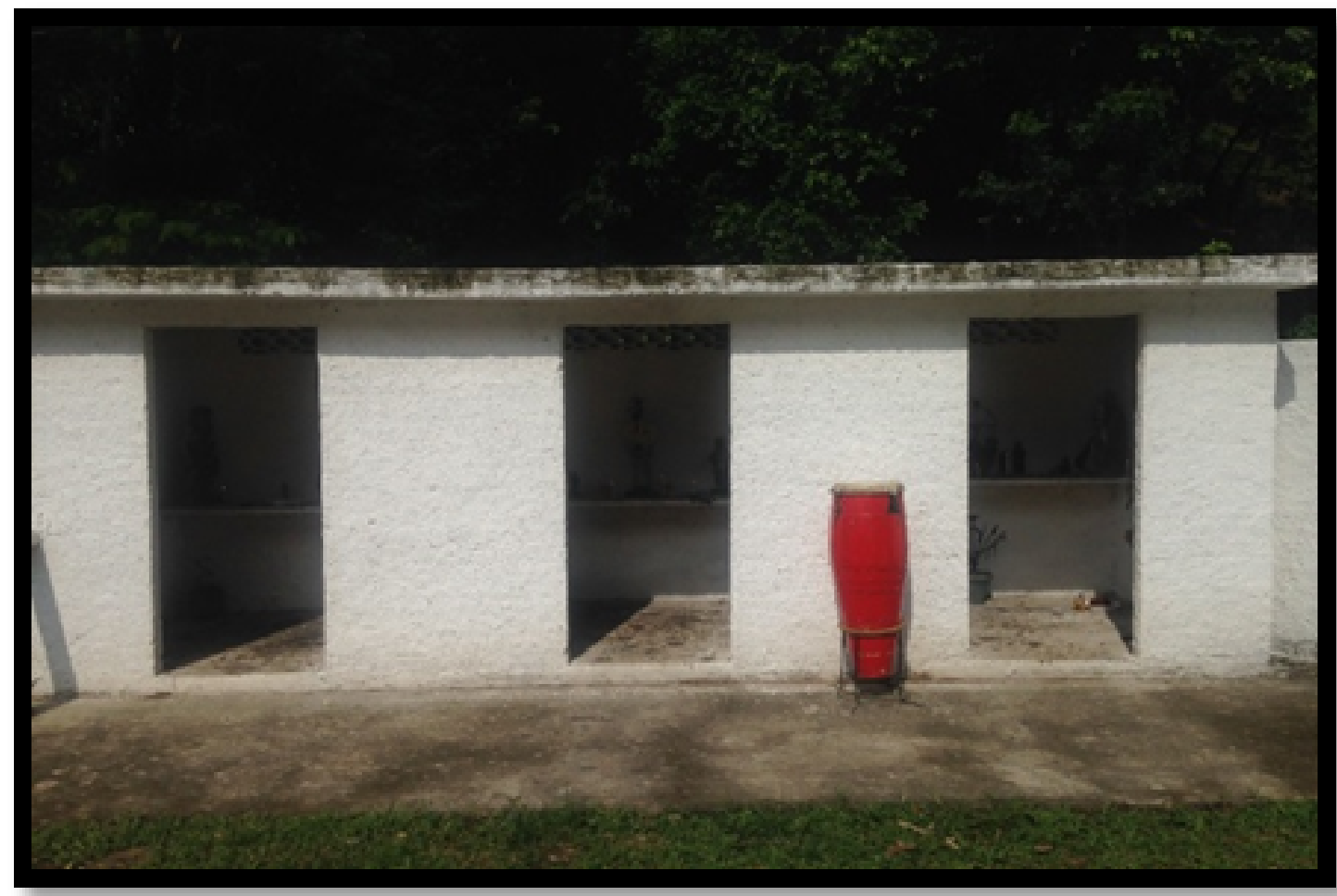

Fonte: Arquivo pessoal (2016 e 2017)

Após a cerimônia inicial, os fiéis se deslocam para a área alugada (Figura 6), em meio à mata e próximo à cachoeira, onde, naquele momento, será construído o espaço sagrado e organizam uma "mesa" com as oferendas será depositada. Durante os cultos, ouvem-se os atabaques e os cânticos dos diversos terreiros e/ou centros ali presentes. Quando os médiuns encerram suas atividades, geralmente com um lanche ou almoço, todo o lixo deve ser recolhido e jogado em locais reservados. As oferendas ficarão expostas no local (Figura 7) até o dia seguinte, quando serão recolhidas por funcionários contratados pela administração do parque. 
Revista de Geografia (Recife) V. 35, No. 1 (especial), 2018

Figura 6 - Terreiro no centro da mata no Parque Ecológico dos Orixás, em Magé (RJ)

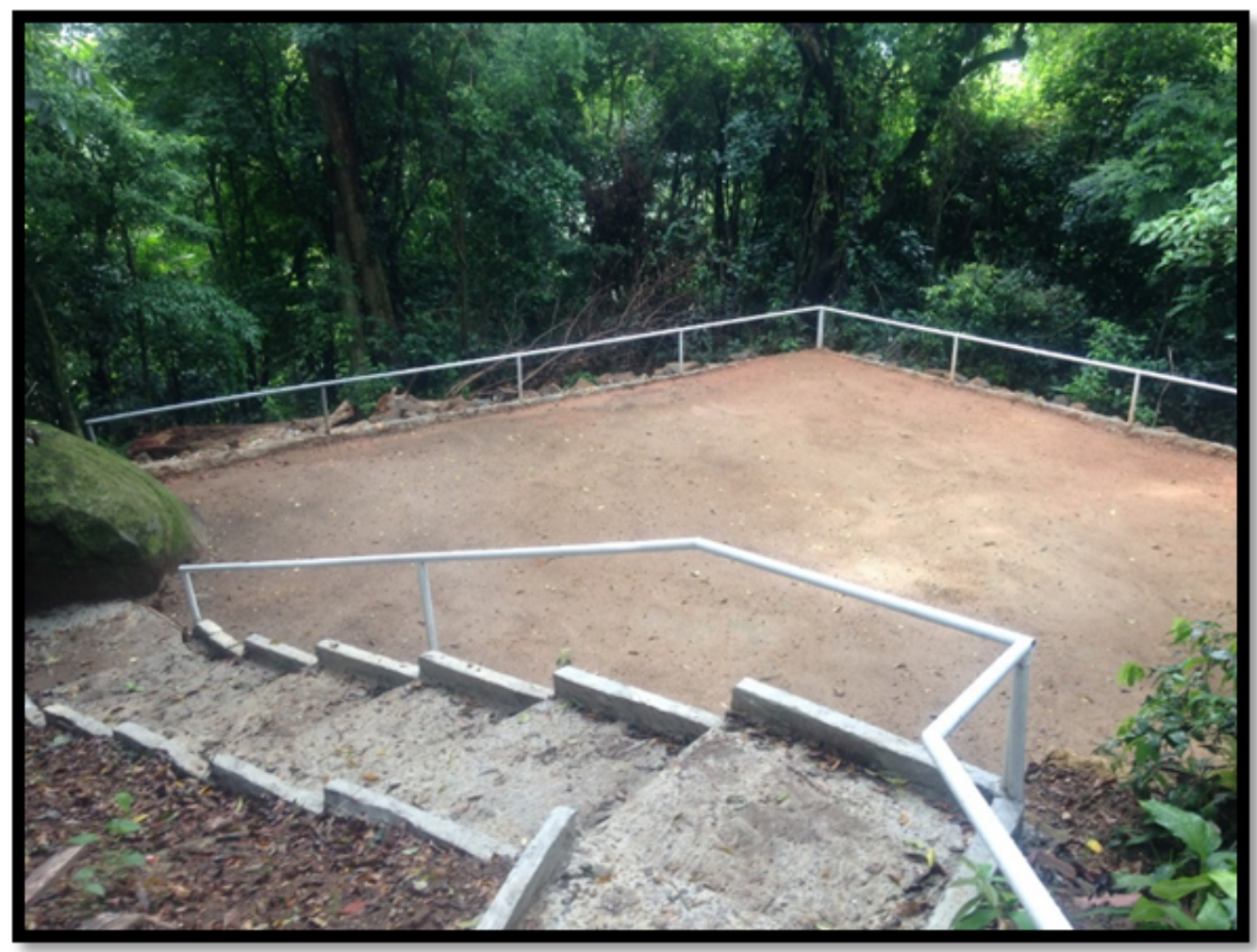

Fonte: Arquivo pessoal, 2016 e 2017 
Figura 7 - Mesa de oferendas para o Orixá Oxóssi, no Parque Ecológico dos Orixás, em Magé (RJ)

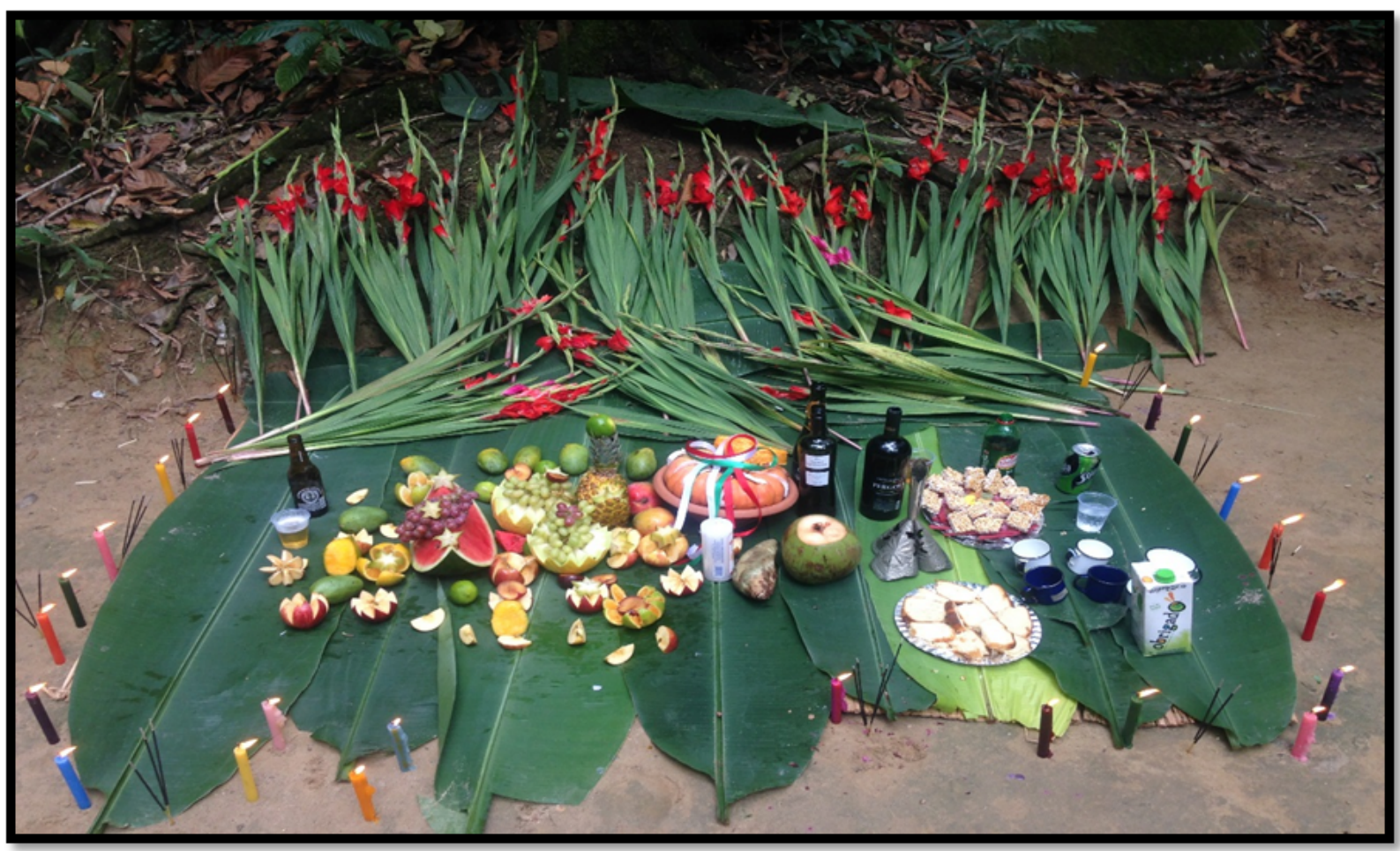

Fonte: Arquivo pessoal, 2017

Ao se filiarem à federação, muitos terreiros, ao pagarem as mensalidades e taxas pelo uso do espaço, obtém serviços essenciais para a realização dos rituais. Para muitos terreiros, como o Grupo Espírita Vó Sá Maria da Bahia, esse espaço tornou-se vital, como na festividade que ocorre no dia 20 de janeiro, tradicional dia de homenagens ao Orixá Oxóssi, energia que tem a força vital presente nas florestas.

Portanto, os serviços oferecidos pela União Umbandista dos Cultos Afro-Brasileiros vão além do acesso aos geossímbolos, mas incluem a organização do estacionamento, do vestiário, da cantina, a segurança e a limpeza dos locais de culto após as cerimônias.

No caso da Tenda Espírita Zurykan, localizada no bairro Sampaio, na Zona Norte da cidade, a necessidade do uso de geossímbolos em espaços públicos se torna menos desafiador. Ao entrarmos na propriedade, os visitantes sobem uma longa escadaria que vai levar à entrada do terreiro. Ao longo da subida, encontramos uma área de mata onde plantas ritualísticas são cultuadas e uma área verde fornece o ponto de força para as entidades/divindades das florestas. No pátio interno da casa, após o salão principal, os fiéis têm à disposição um espaço para a organização dos ritos, além de pontos de força dos espíritos exunizados, como se fossem armários onde as imagens ficam dispostas. Essas entidades, geralmente cultuadas nas 
estradas, ruas e encruzilhadas, são reverenciadas no espaço interno do terreiro. Há também, com o intuito de cultuar, principalmente as almas, réplicas do Cruzeiro das Almas, comuns em cemitérios (Figura 8).

Figura 8 - Cruzeiro das Almas. Tenda Espírita Zurykan

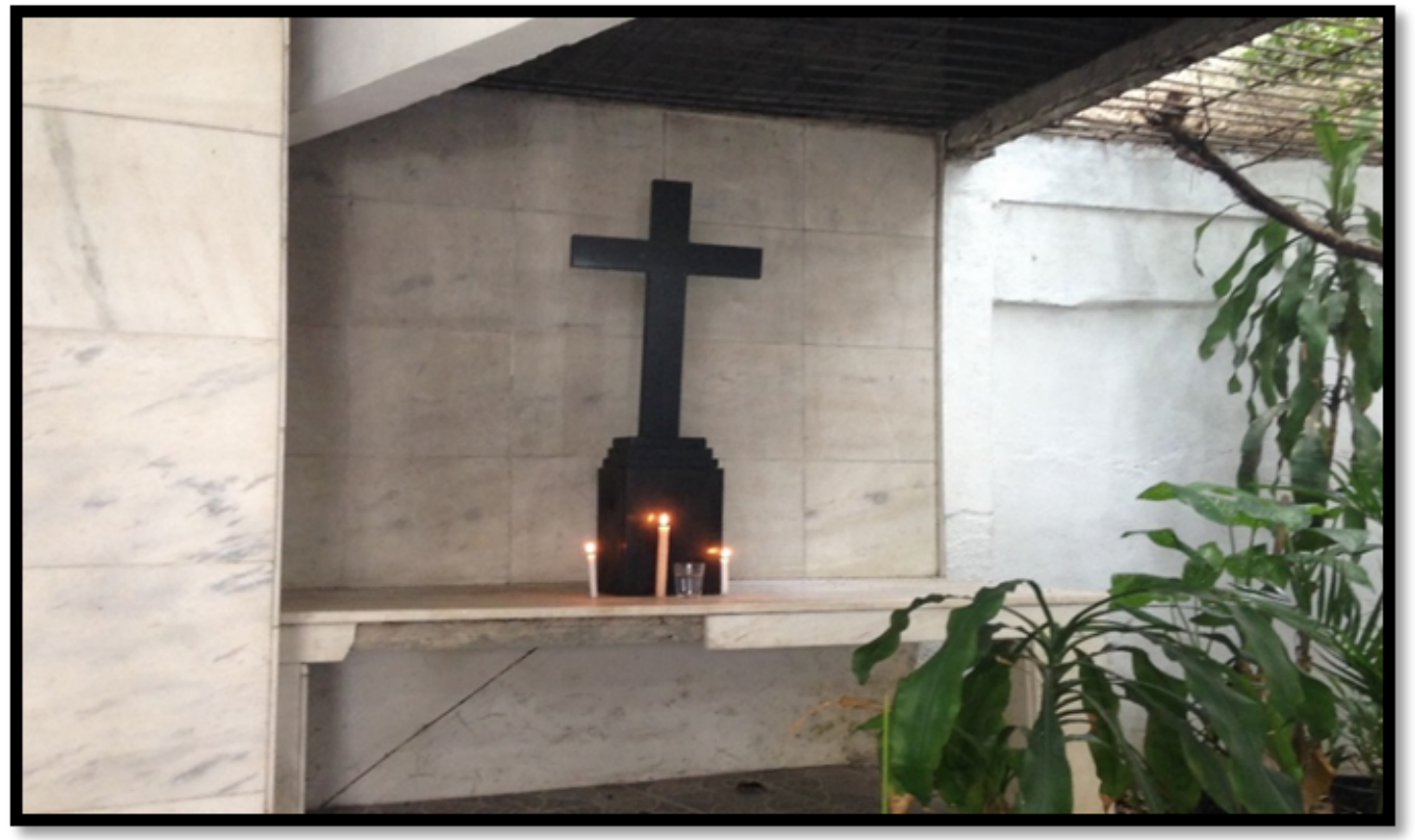

Fonte: Arquivo pessoal (2016)

Contando com uma propriedade bastante extensa, o terreiro possui também a réplica de uma cachoeira e um bloco rochoso. Sendo assim, os crentes podem realizar seus rituais e fazer suas oferendas, respectivamente, aos orixás Oxum e Xangô (Figuras 9 e 10). Isso revela que a principal estratégia espacial do grupo umbandista está em criar, no espaço privado do terreiro, os geossímbolos que caracterizam os sítios sagrados para os rituais umbandistas. 
Figuras 9 e 10- Pontos de força dos orixás Oxum (cachoeira) e Xangô (pedreira). Tenda Espírita Zurykan
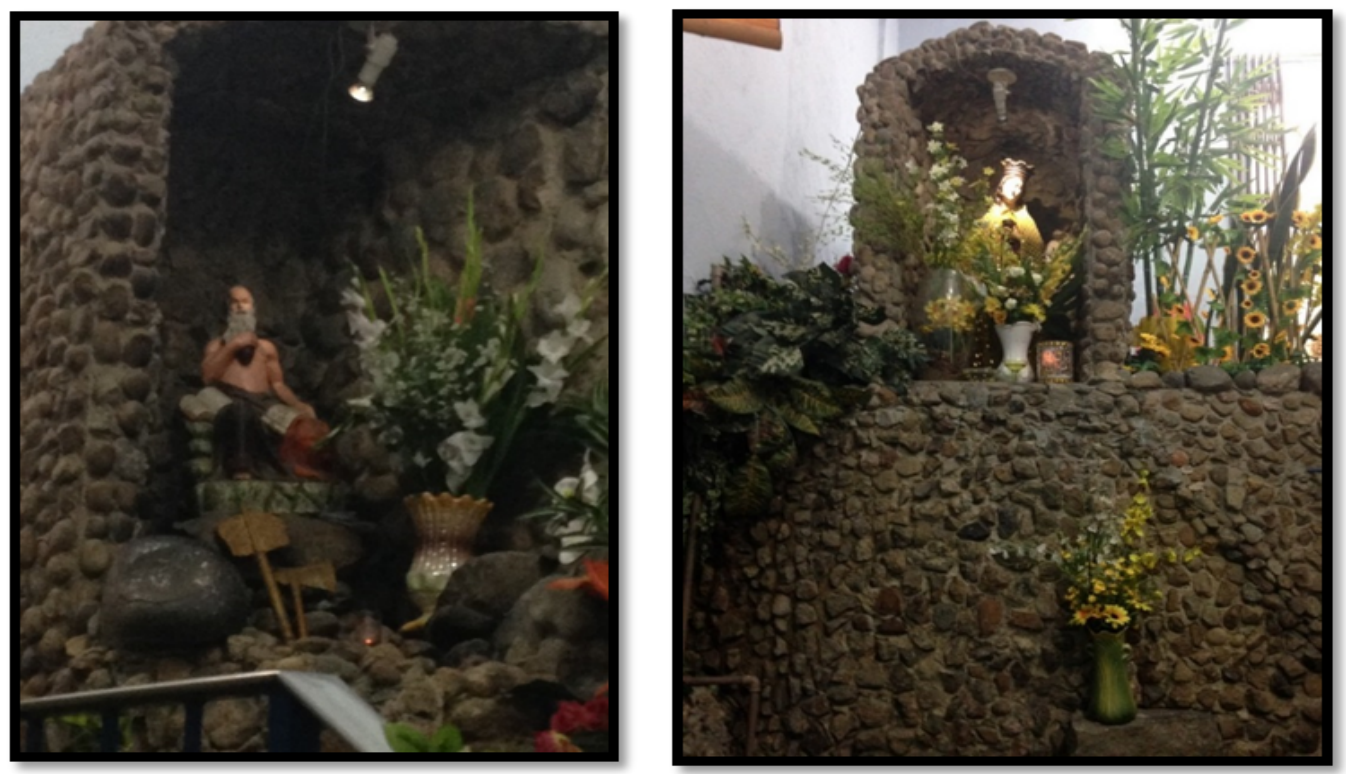

Fonte: Arquivo pessoal, 2016

\section{CONCLUSÕES}

Como vimos, o espaço é essencial para a realização das práticas rituais umbandistas, seja ele privado ou público. Os desafios, no entanto, são muitos. Para os umbandistas. Tornase fundamental, portanto, a criação de estratégias espaciais que possam viabilizar o exercício legal de culto, garantido pela Constituição Federal de 1988. Estas estratégias podem ser apresentadas como instrumentos de conquista cidadã de grupos sociais menos atuantes nas decisões político-espaciais, permitindo vislumbrar práticas espaciais que possam definir padrões de sustentabilidades próprios num ambiente democrático.

No que tange às duas estratégias pesquisadas no trabalho em tela, tiramos algumas conclusões, a saber:

a) A construção e o uso de espaços privados para rituais, como o Parque Ecológico dos Orixás no Município de Magé, no estado do Rio de Janeiro, revela que, apesar das federações responsáveis pela administração atenderem às necessidades de muitos grupos religiosos afrobrasileiros diante da carência de espaços "naturais" para rituais e demonstrarem uma preocupação com a preservação do território santuário, podemos perceber que, ao promover uma espécie de tutela sobre os terreiros e indivíduos, as federações não geram, de fato, uma conscientização dos devotos na gestão de suas práticas, além de não promover, consequentemente, a educação ambiental dos praticantes. Cabe ressaltar que há diferenças no 
tratamento dado, pelos devotos, aos espaços públicos e aos privados em relação à obediência das regras estabelecidas. No Parque Ecológico dos Orixás (Magé-RJ), por exemplo, as regras exigidas são cumpridas e a relação com o espaço revela uma prática com maior sustentabilidade ambiental. No que tange ao uso de espaços públicos, percebemos que, apesar de normatizados pelo poder público, não há, por parte de muitos fiéis, uma relação de respeito ao ambiente, provocando poluição dos pontos de força das divindades e entidades cultuadas.

b) A construção de geossímbolos em espaços privados consiste em criar, no espaço privado do terreiro, os objetos que caracterizam os sítios sagrados para os rituais umbandistas, como cachoeiras, áreas de floresta e pedreiras. Apesar de ser uma estratégia que evita conflitos e poluição dos pontos de força nos espaços públicos, fica restrita àqueles grupos que possuem propriedades privadas.

c) A preocupação com a sustentabilidade ambiental se revela como uma estratégia de conscientização entre os fiéis sobre os riscos e consequências ambientais das oferendas, visando legitimar as práticas religiosas diante da opinião pública. No entanto, diante de tecidos, copos, sacos plásticos, estilhaços de garrafas, alguidares, frutas e até animais sacrificados deixados nos locais onde são feitos os rituais, entendemos que o desconhecimento, por parte de muitos devotos, dos fundamentos da legislação ambiental, assim como dos fundamentos da própria religião, ainda colabora com a destruição dos geossímbolos.

\section{REFERÊNCIAS}

ALMEIDA, R.; BARBOSA, R.J. Transição religiosa no Brasil. In: ARRETCHE, M (org). Trajetórias das desigualdades: como o Brasil mudou nos últimos cinquenta anos. São Paulo: Editora UNESP, CEM, 2015.

BONNEMAISON, J.. Viagem em torno do território. In: CORRÊA, Roberto Lobato e ROSENDAHL, Zeny. (orgs). Geografia cultural: um século (3). Rio de Janeiro: Editora Uerj, 2002.

BROWN, D. DeG. Umbanda: religion and politics in urban Brazil. New York: Columbia University Press, 1986.

http://oglobo.globo.com/rio/religioes-africanas-merce-da-intolerancia-8471972. Acesso em: 28 de agosto de 2013.

http://www.solascriptura-tt.org. Acesso em 08 de abril de 2009. 
MORAES, R. O. Terreiros de Candomblés no Rio de Janeiro: Territórios e Estratégias Identitárias nas Práticas Simbólicas e Sociais. Dissertação de mestrado. Universidade Federal Fluminense, 2009.

MORAIS, M. A. Espaço e expressões religiosas: teoria e prática na geografia escolar. In: AZEVEDO, D. A. ; D. A.; MORAIS, M. A. (orgs). Ensino de Geografia: novos temas para a geografia escolar. Consequência, 2014.

MORAIS, M. A. Umbanda e Meio Ambiente: o culto a Oxossi e as florestas. Rio de Janeiro: Ideia Jurídica Ltda, 2013.

MORAIS, M. A. Umbanda, territorialidade e Meio Ambiente: Representações socioespaciais e Sustentabilidades. Dissertação de Mestrado. Pontifícia Universidade Católica do Rio de Janeiro, 2010.

MORAIS, M. A. Umbanda: entidades e orixás. Rio de Janeiro: Novo Ser, 2014.

MORAIS, M. A. Umbanda: uma religião essencialmente brasileira. Rio de Janeiro: Novo Ser, 2012.

MOTA, F. R. Cidadãos em toda parte ou cidadãos à parte? Demandas de direitos e reconhecimento no Brasil e na França. Rio de Janeiro: Consequência, 2014.

ROSENDAHL, Z.. Espaço e Religião: uma abordagem geográfica. Rio de Janeiro: Editora Uerj, 2002.

VICTORIANO, B. A. D.. O prestígio religioso na umbanda: dramatização e poder. São Paulo: Annablume, 2005.

www.pime.org.br. Acesso em 09/04/ 2009. 